\title{
Thermal and fire behavior of natural fibers/PBS biocomposites
}

\author{
G. Dorez, A. Taguet*, L. Ferry, J.M. Lopez-Cuesta \\ Centre de Recherche CMGD, Ecole des Mines d'Alès, 6 avenue de Clavières, F-30319 ALES Cedex, France
}

\section{A B S T R A C T}

This paper investigates and compares the thermal degradation and fire reaction of different natural fibers and their corresponding biocomposites. Polybutylene succinate (PBS) was used as polymer matrix. Cellulose, hemp, flax, sugar cane and bamboo were used as natural fibers and ammonium polyphosphate (APP) was used as fire retardant agent. The influence of fiber type, fiber content and the addition of APP were investigated using TGA, PCFC and cone calorimetry.

The incorporation of fibers in PBS reduces the thermal stability, and the time to ignition (TTI) of biocomposites, but it increases the mass residue corresponding to the formation of a char barrier. These results are ascribed to the components of fibers, and the flammability of the gas released by the lignocellulosic fibers. The fiber content does not influence the TTI, but affects significantly the peak of heat released rate (pHRR). Thus, a minimum content of fibers is required to form a protective barrier during fire test. The addition of APP in the biocomposite leads to hot hydrolysis of PBS and phosphorylation of flax. Hence, the fire retarded biocomposite forms a barrier layer due to the charring of the matrix and the preservation of the fiber skeleton and therefore shows a significant decrease of the pHRR.

Keywords:

PBS

Ammonium polyphosphate

Natural fibers

Biocomposites

\section{Introduction}

With the increase of environmental consciousness, the use of bio-based materials has proved to be an effective solution to reduce the production of oil-based plastics. Recently, polybutylene succinate (PBS) has received a great interest, since bio-based succinic acid and butanediol can now be obtained [1]. PBS is particularly attractive due its high processability, good thermal stability and high toughness related to its low glass transition. However, in applications where good mechanical properties are required, this biopolymer needs to be reinforced by fibers. To keep the bio-based characteristics of composites, it is interesting to use natural fibers such as hemp, flax or bamboo as reinforcement.

The use of natural fibers in biocomposites has several advantages such as low cost, low density, proper mechanical properties and of course availability from renewable resources. However, the poor compatibility with hydrophobic polymer matrices, the thermal sensitivity at the temperature of compounding processes and the flammability of those fibers could limit the use of the corresponding biocomposites. If the improvement of the fibermatrix compatibility has generated many research papers [2-5], there are only few reports on the improvement of the thermal stability and the fire behavior. Hapuarachchi and Peijs [6]

\footnotetext{
* Corresponding author. Tel.: +33 (0)4 667856 87; fax: +33 (0)4 66785365 E-mail address: aurelie.taguet@mines-ales.fr (A. Taguet).
}

incorporated multiwalled carbon nanotubes and sepiolite nanoclays as flame retardant in a biocomposite based on polylactic acid (PLA) and hemp. The incorporation of flame retardant in the system based on PLA decreased significantly the peak of heat release rate (pHRR) but the reduction is lower when natural fibers were added. Some authors studied the addition of phosphorous agent in biocomposites. Suardana et al. [7] treated coconut and jute fibers with diammonium phosphate (DAP) and incorporated them in thermoplastic matrices. The increase of DAP percentage improved the flame resistance and the formation of a char at $500{ }^{\circ} \mathrm{C}$ but decreased the flexural and tensile strengths. In this article, no attention was paid on the origin of the link formed between the fibers and DAP molecules but in some studies phosphorous compounds could be covalently grafted on natural fibers. Chaiwong et al. [8] treated silk fibers with a phosphorous based agent using argon jet plasma. Using this technique, they achieved durable flame retardancy properties (with a char formation). Ammonium polyphosphate (APP) is often used to fireproof polymers and composites. Matkò et al. [9] studied its efficiency as charring agent of the polysaccharides in cellulose and starch bio-based composites. The results indicated that both matrix (polyurethane) and natural fibers participate in the mechanism of flame retardancy. More recently, Shumao et al. [10] studied the influence of APP on the flame retardancy of a ramie fiber-reinforced poly(lactic acid). The authors varied the incorporation of APP either in PLA (FPLA-NF) or in natural fibers (PLAFNF) or in both compounds (FPLA-FNF). They obtained a better 
flame retardancy for FPLA-FNF composites and suggested a charring process leading to the formation of phosphate ramie. Chen et al. [11] investigated the combustion property of ultrafine microencapsulated ammonium polyphosphate in a ramie fiberreinforced poly(L-lactic acid). The interaction and the good distribution of the microencapsulated ammonium polyphosphate led to improve the anti-dripping properties of the composites.

In this study, five different natural fibers (cellulose, hemp, flax, sugar cane, and bamboo) have been used as reinforcement of a polybutylene succinate thermoplastic matrix (PBS). The aim of this work is to study the thermal stability and the fire behavior of the above-mentioned natural fibers and their corresponding PBS biocomposites. This paper will particularly focus on flax-based composites and on the influence of fiber content. Finally, ammonium polyphosphate will be incorporated in PBS biocomposite in order to study char formation and fire retardant properties.

\section{Experimental}

\subsection{Materials}

Poly(lactic acid) 7000D was purchased from Naturworks. Poly(1,4-butanediol succinate) (PBS film grade 1903F, from Xinfu Pharm) was used as matrix and dried $\left(24 \mathrm{~h}\right.$ at $60{ }^{\circ} \mathrm{C}$ ) before compounding. Cellulose (Arbocel BC1000, from J. Rettenmeier \& Söhne GMBH), flax (Fibras-S6B, from FRD), hemp (from Chanvrière de l'Aube), bamboo (grade 3, from Bamboo Fibers Technology) and sugar cane (from Centro Universitario Fundaçao Santo André, Avenida Príncipe de Gales, 821 - Príncipe de Gales Santo André, Brazil) were used as natural fibers. The chemical composition of the fibers is shown in Table 1 [12-14]. The fibers were totally dried $\left(1 \mathrm{~h}\right.$ at $\left.105{ }^{\circ} \mathrm{C}\right)$ before compounding. Ammonium polyphosphate (APP-Exolit AP 423 from Clariant) was used as fire retardant agent.

The chemical composition of the flax and the sugar fibers was obtained from Fibres Recherches et Développement and the Centro Universitario Fundaçao Santo André, Materials Science and Engineering, Brazil, respectively.

\subsection{Composite preparation}

The composites were obtained by mixing PBS pellets and natural fibers in a Haake Rheomix internal mixer (100 rpm at $110^{\circ} \mathrm{C}$ ). PBS was firstly introduced in the chamber of the internal mixer and mixed for 2.5 min until a constant torque was obtained. Then, for the fire retarded biocomposite, the ammonium polyphosphate was added and mixed with the matrix for 2 min. Finally, the fibers were added progressively during $9 \mathrm{~min}$. After the final fiber addition, the mixing was extended for $2 \mathrm{~min}$. The total time of blending was around $15 \mathrm{~min}$. Sample compositions and designations are given in Table 2 .

All materials were compression molded at 110 bars into $100 \times 100 \times 4 \mathrm{~mm}^{3}$ square sheets of around $50 \mathrm{~g}$ for the biocomposites and $25 \mathrm{~g}$ for the fibers.

Table 1

Chemical composition of the different natural fibers.

\begin{tabular}{lllll}
\hline Fibers & Cellulose (\%) & Hemicellulose (\%) & Lignin (\%) & Ash (\%) \\
\hline Cellulose & 100 & 0 & 0 & 0 \\
Flax & 80 & 13 & 2 & 1 \\
Hemp & $70-77$ & $17.9-22.4$ & $3.7-5.7$ & 0.8 \\
Sugar cane & $32-34$ & $27-32$ & $19-24$ & $1.5-5$ \\
Bamboo & $26-49$ & $15-27.7$ & $21-31$ & $1.3-2$ \\
\hline
\end{tabular}

Table 2

Content of PBS, APP, and natural fibers for all biocomposites.

\begin{tabular}{lcll}
\hline Designation & $\%$ PBS & \% Natural fiber (origin) & $\%$ APP \\
\hline PBS & 100 & 0 (sugar cane) & 0 \\
70PBS30sug & 70 & 30 (cellulose) & 0 \\
70PBS30cel & 70 & 30 (hemp) & 0 \\
70PBS30hem & 70 & 30 (bamboo) & 0 \\
70PBS30bam & 70 & 30 (flax) & 0 \\
70PBS30fl & 70 & 20 (flax) & 0 \\
80PBS20fl & 80 & 15 (flax) & 0 \\
85PBS15fl & 85 & 10 (flax) & 0 \\
90PBS10fl & 90 & 0 & 0 \\
95PBS5APP & 95 & 30 (flax) & 5 \\
65PBS5APP-30fl & 65 & & 5 \\
\hline
\end{tabular}

\subsection{Characterization}

\subsubsection{Thermogravimetric analysis (TGA)}

A Perkin Elmer Pyris-1 Thermogravimetric Analyzer instrument was used to analyze the thermal decomposition of the fibers, pure matrix and biocomposites. Sample weights of around $10 \mathrm{mg}$ were heated from 50 to $700{ }^{\circ} \mathrm{C}$ at a heating rate of $10{ }^{\circ} \mathrm{C} \mathrm{min}{ }^{-1}$ under nitrogen atmosphere. Residual weight (Mass Res.), degradation temperature at $20 \%$ mass loss $\left(T_{20 \%}^{\circ}\right)$ and maximum of DTG curve (DTG) were determined.

\subsubsection{Cone calorimeter test}

A Fire Testing Technology (FTT) cone calorimeter was used to evaluate fire reaction properties. The $100 \times 100 \times 4 \mathrm{~mm}^{3}$ samples were exposed to a radiant heat flux of $35 \mathrm{~kW} / \mathrm{m}^{2}$. This flux corresponds to common heat flux in a mild scenario. Heat release rate (HRR) was measured as function of time and time to ignition (TTI), Total Heat Release, (THR, the integral of the heat release rate), peak of Heat Release Rate (pHRR), Effective Heat Combustion (EHC, the heat released per gram of mass loss), and the maximum average of heat emission (MARHE) were determined. The ARHE was calculated according to (Eq. (1)) [15].

$\operatorname{ARHE}\left(t_{n}\right)=\frac{\sum_{2}^{n}\left(\left(t_{n}-t_{n-1}\right) \times \frac{q_{n}+q_{n-1}}{2}\right)}{t_{n}-t_{0}}$

where $t_{n}$ is the time, and $q_{n}$ : rate of heat release at $t_{n}$.

\subsubsection{Pyrolysis combustion flow calorimeter (PCFC)}

Pyrolysis combustion flow calorimeter is a technique developed by Lyon and Walters [16] to investigate fire behavior of samples at microscopic scale. Sample weights of around $2 \mathrm{mg}$ are pyrolyzed at $1{ }^{\circ} \mathrm{C} / \mathrm{s}$ and the degradation products are transported by inert gas flux. Then, there are mixed with oxygen before entering a combustor at $900{ }^{\circ} \mathrm{C}$ where the products are completely oxidized. The heat release rate was measured as a function of temperature. The values of peak of Heat Release Rate (pHRR), temperature of pHRR $\left(T_{\text {peak }^{\circ}}\right)$, Total Heat Released (HR) which is the integral of the heat release rate over the duration of the experiment, and Effective Heat Combustion (EHC), which corresponds to the heat released per gram of mass loss were determined.

\subsubsection{Scanning electron microscopy (SEM)}

The micrographs of the fibers before and after pyrolysis were obtained using an environmental scanning electron microscope (FEI Quanta SEM) equipped with a scanning transmission electron microscopy detector (STEM). Micrographs were obtained under high vacuum at a voltage of $20 \mathrm{kV}$ with a spot size of $3.0 \mathrm{~nm}$ and a working distance of $10.4 \mathrm{~mm}$. 

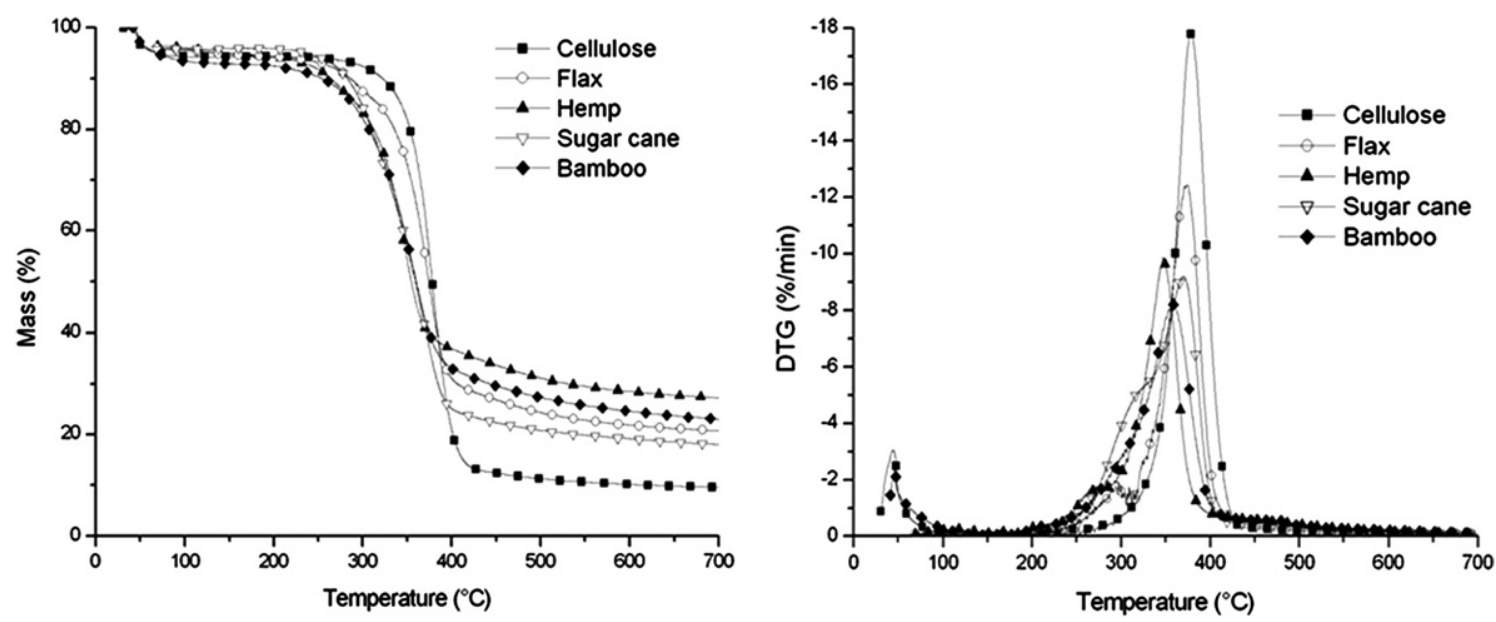

Fig. 1. TGA curves of the different natural fibers.

\section{Results and discussion}

\subsection{Thermal and fire behavior of natural fibers}

The thermal degradation of pure cellulose and lignocellulosic natural fibers has been widely studied and it is well known that the

Table 3

Thermogravimetric parameters of the different natural fibers.

\begin{tabular}{lll}
\hline Natural fibers & Mass Res at $700{ }^{\circ} \mathrm{C}(\%)$ & $T_{20 \%}\left({ }^{\circ} \mathrm{C}\right)$ \\
\hline Cellulose & 10 & 353 \\
Flax & 21 & 335 \\
Hemp & 27 & 312 \\
Sugar cane & 18 & 309 \\
Bamboo & 23 & 307 \\
\hline
\end{tabular}

Table 4

PCFC values of the different natural fibers.

\begin{tabular}{lllll}
\hline Natural fibers & pHRR $(\mathrm{W} / \mathrm{g})$ & $T_{\text {peak }}^{\circ}\left({ }^{\circ} \mathrm{C}\right)$ & $\mathrm{HR}(\mathrm{kJ} / \mathrm{g})$ & $\mathrm{EHC}(\mathrm{kJ} / \mathrm{g})$ \\
\hline Cellulose & 244 & 376 & 12.3 & 13.7 \\
Flax & 115 & 372 & 5.6 & 7.1 \\
Hemp & 87 & 334 & 4.3 & 5.9 \\
Sugar cane & 127 & 383 & 9.6 & 11.7 \\
Bamboo & 101 & 361 & 7.0 & 9.1 \\
\hline
\end{tabular}

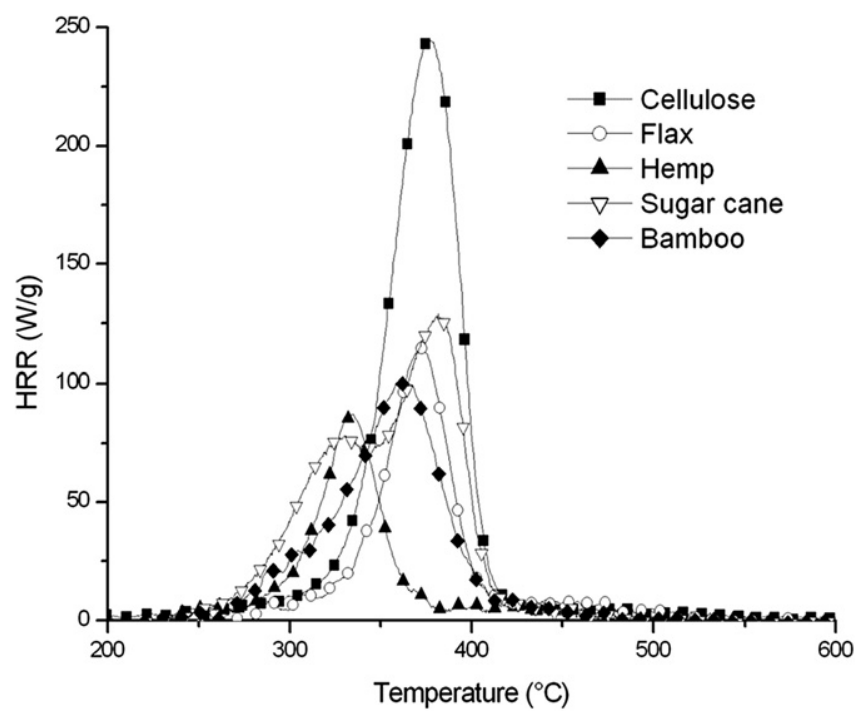

Fig. 2. PCFC curves of the different natural fibers. degradation of the lignocellulosic fibers occurs in four principal steps [17-21]. The first mass loss region between 50 and $150{ }^{\circ} \mathrm{C}$ is attributed to the release of water absorbed by the fibers. The second step between 250 and $370{ }^{\circ} \mathrm{C}$ corresponds to the depolymerization of the hemicellulose and the cleavage of glycosidic linkages of cellulose. The main peak between 340 and $370^{\circ} \mathrm{C}$ is assigned to the degradation of the $\alpha$-cellulose. The thermal degradation of the cellulose occurs in several steps [18,22]. It involves a number of processes including: the desorption of adsorbed water, crosslinking of cellulose chains with the evolution of water to form dehydrocellulose, decomposition of the dehydrocellulose to yield char and volatiles, formation of levoglucosan, decomposition of the levoglucosan to yield flammable and nonflammable volatiles and gases, tar, and char $[18,22]$. Concerning the lignin, the degradation temperature range is larger (from $200{ }^{\circ} \mathrm{C}$ to $500{ }^{\circ} \mathrm{C}$ ) [23]. From

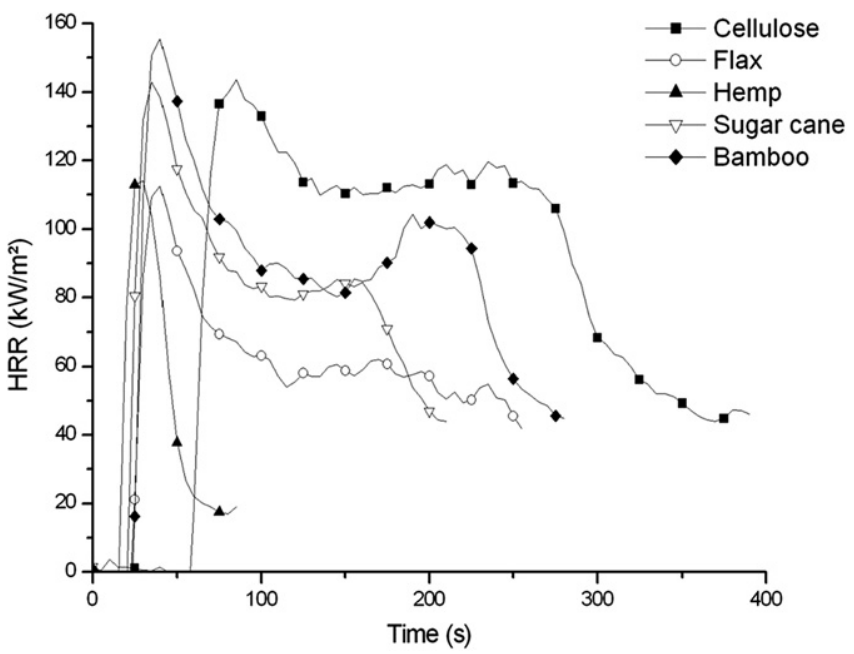

Fig. 3. Cone calorimeter curves of the different natural fibers

Table 5

Cone calorimeter values for the different natural fibers.

\begin{tabular}{lrlrll}
\hline Natural fibers & TTI $(\mathrm{s})$ & pHRR $\left(\mathrm{kW} / \mathrm{m}^{2}\right)$ & THR $(\mathrm{kJ})$ & Mass Res $(\%)$ & MARHE $\left(\mathrm{kW} / \mathrm{m}^{2}\right)$ \\
\hline Cellulose & 50 & 144 & 234 & 12 & 91.2 \\
Flax & 16 & 112 & 130 & 47 & 60.5 \\
Hemp & 9 & 114 & 32 & 65 & 58.1 \\
Sugar cane & 13 & 143 & 143 & 25 & 81.8 \\
Bamboo & 17 & 155 & 205 & 26 & 88.7 \\
\hline
\end{tabular}



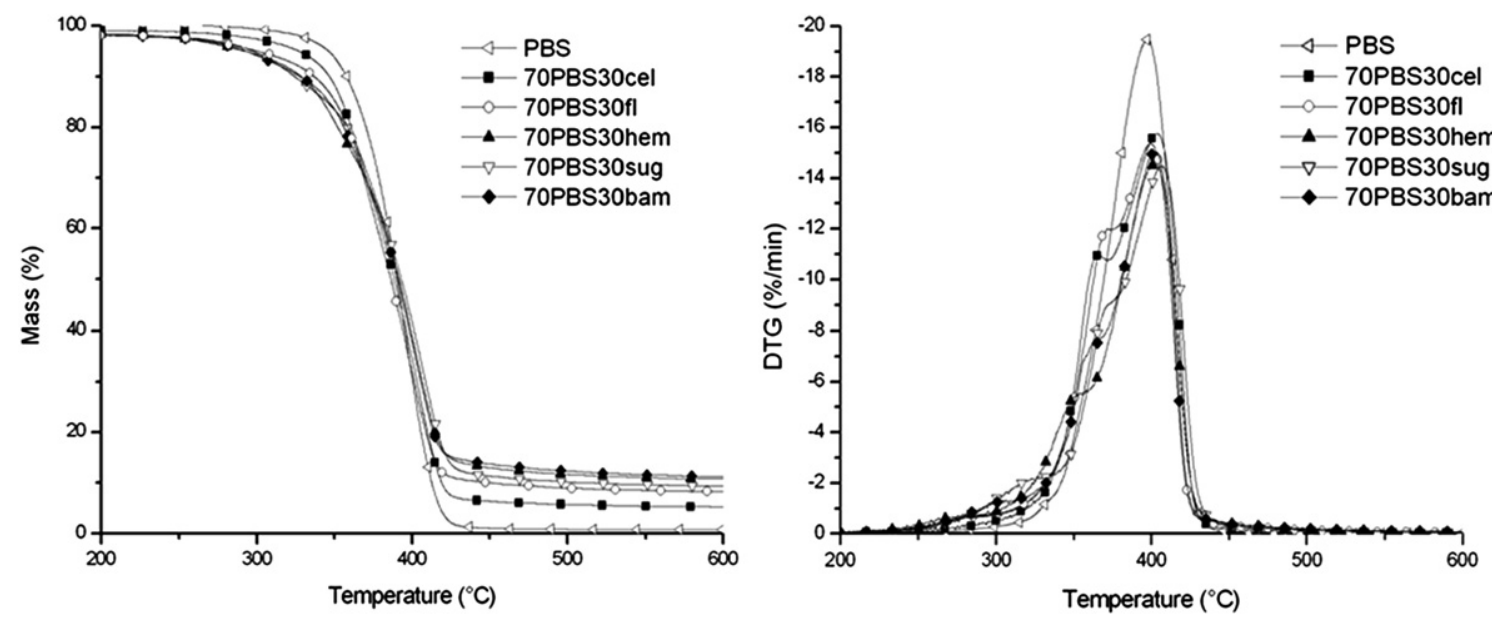

Fig. 4. TGA curves of biocomposites based on various natural fibers.

$200{ }^{\circ} \mathrm{C}$ to around $300{ }^{\circ} \mathrm{C}$, weak bonds break, whereas at higher temperature a cleavage of stronger bonds in aromatic rings occurs. This explains the better thermal stability of flax compared to the other lignocellulosic fibers (Table 1 and Fig. 1), since a lower lignin content improves thermal stability. The mass loss up to $430{ }^{\circ} \mathrm{C}$ is due to the degradation of the lignin and the final decomposition of cellulose, both leading to the formation of a char (Fig. 1). The results obtained in Fig. 1 are in good agreement with the above comments as pure cellulose has a better thermal stability than lignocellulosic fibers (that contain lignin with weak bonds). But cellulose gives a lesser amount of char, whereas lignocellulosic fibers can form from 18 to $27 \mathrm{wt} \%$ of charred residue (Table 3 ).

By comparing the temperature of HRR peaks obtained at PCFC, it can also be concluded that the thermal stability of pure cellulose is generally better than that of lignocellulosic fibers (Table 4 and Fig. 2), since lignocellulosic fibers start to degrade at lower temperatures than cellulose. As mentioned previously, this is ascribed to the depolymerization of hemicellulose and the scission of weak bonds in lignin [23]. However, the combustion of cellulose is the most exothermic with $12.3 \mathrm{~kJ} / \mathrm{g}$ as total heat release (HR) and $244 \mathrm{~W} / \mathrm{g}$ as peak of heat release rate. The lower pHRR and HR of lignocellulosic fibers indicate that the pyrolysis gases of hemicellulose and especially lignin exhibit low combustion energy. Hence, a high content of cellulose could increase the flammability of fibers $[14,20]$. The effective heat of combustion (EHC) of the natural fibers is scattered $(5.9-13.7 \mathrm{~kJ} / \mathrm{g})$. The presence of

Table 6

TGA values of biocomposites based on various natural fibers.

\begin{tabular}{lcll}
\hline Biocomposites & Mass Res at $700{ }^{\circ} \mathrm{C}(\%)$ & Mass $\operatorname{Res}_{\text {theo }}(\%)$ & $T_{20 \%}\left({ }^{\circ} \mathrm{C}\right)$ \\
\hline PBS & 0.75 & 0 & 370 \\
70PBS30cel & 4.9 & 3.5 & 360 \\
70PBS30fl & 8.2 & 6.8 & 358 \\
70PBS30hem & 10.4 & 8.6 & 352 \\
70PBS30sug & 8.9 & 5.9 & 358 \\
70PBS30bam & 10.6 & 7.4 & 356 \\
\hline
\end{tabular}

Table 7

PCFC values of biocomposites based on various natural fibers.

\begin{tabular}{llllll}
\hline Biocomposites & pHRR $(\mathrm{W} / \mathrm{g})$ & $\mathrm{pHRR}_{\text {theo }}(\mathrm{W} / \mathrm{g})$ & $T_{\text {peak }}\left({ }^{\circ} \mathrm{C}\right)$ & $\mathrm{HR}(\mathrm{kJ} / \mathrm{g})$ & $\mathrm{EHC}(\mathrm{kJ} / \mathrm{g})$ \\
\hline PBS & 394 & - & 410 & 18.4 & 18.5 \\
70PBS30cel & 275 & 349 & 420 & 14.9 & 15.7 \\
70PBS30fl & 309 & 310 & 423 & 16.8 & 18.3 \\
70PBS30hem & 272 & 302 & 418 & 15.0 & 16.7 \\
70PBS30sug & 291 & 313 & 418 & 15.0 & 16.5 \\
70PBS30bam & 293 & 360 & 413 & 15.1 & 16.9 \\
\hline
\end{tabular}

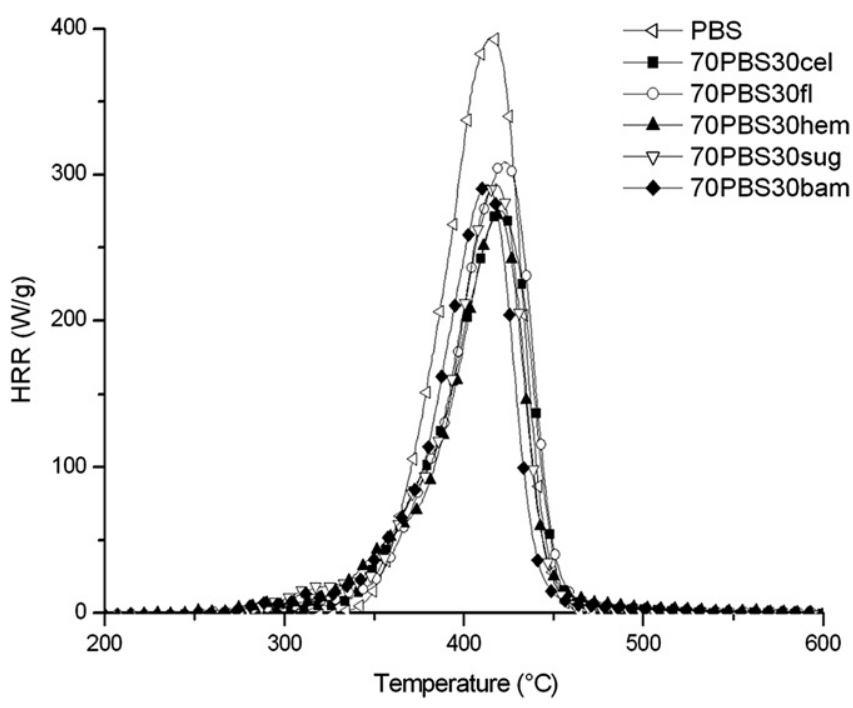

Fig. 5. PCFC curves of biocomposites based on various natural fibers.

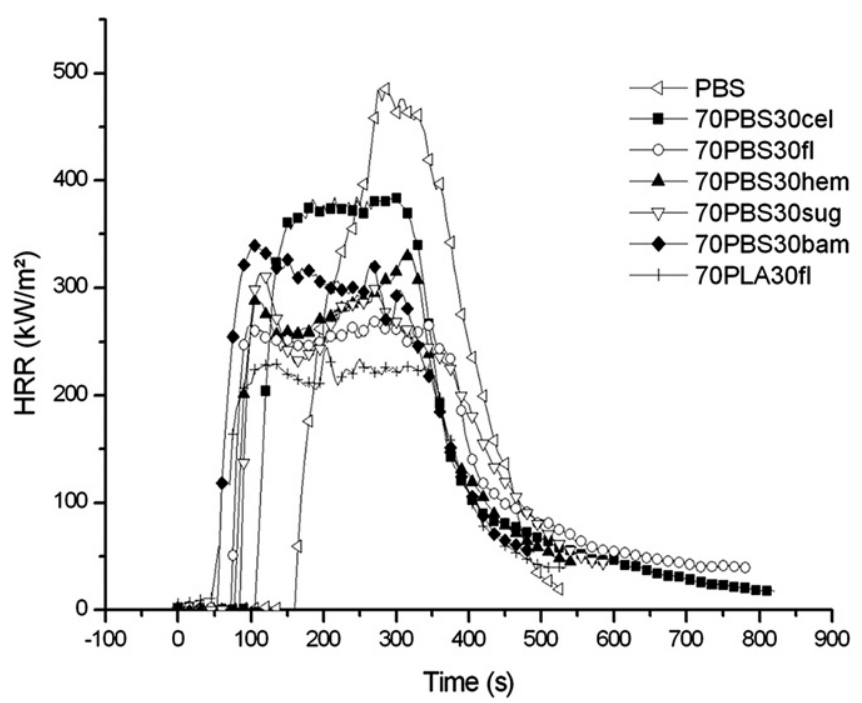

Fig. 6. HRR (cone calorimeter) of the composites with PBS and various natural fibers. 


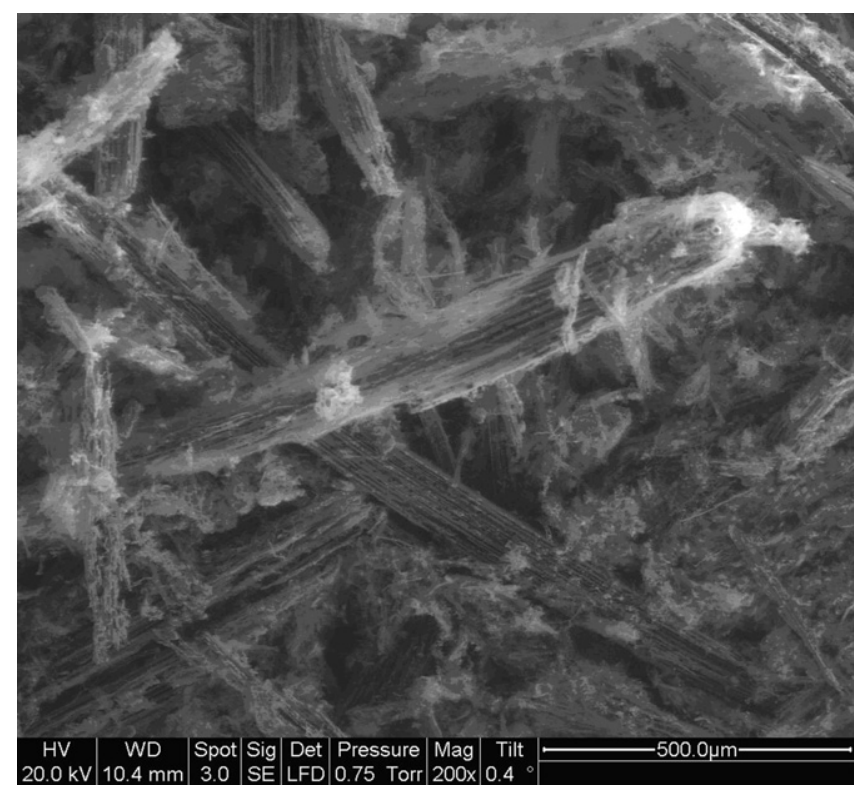

Fig. 7. Micrograph of the core of the 70PBS30bam after cone calorimeter test.

hemicellulose and lignin accelerates ignition but reduces EHC compared to pure cellulose.

TGA and PCFC results are consistent with the results obtained with cone calorimeter. Lignocellulosic fibers start to decompose at lower temperature than pure cellulose, releasing less flammable gases than pure cellulose. The first statement results in a lower time to ignition (TTI) for fibers containing hemicellulose and lignin than for pure cellulose (Fig. 3 and Table 5), whereas, the second statement leads, to a lower THR for flax, hemp, sugar cane and bamboo fibers than for pure cellulose. Pure cellulose is more flammable, because of the formation of highly flammable levoglucosan. The presence of lignin in fiber composition inhibits the thermal decomposition of levoglucosan, and reduces the flammability of the fibers [24]. Other parameters could influence the formation of the levoglucosan and the flammability of the fibers such as crystallinity and fibrillar orientation [25]. The MARHE (maximum rate of heat emission) can be considered as a good measure of the propensity for a fire development in the case of a real situation. In this case, the flax and the hemp would be the most effective natural fibers. It should be noted that in the case of hemp the HRR rapidly decreases before extinction. This result is related to the low compactness of hemp plate compared to the other samples after compression molding. The mass residues obtained at cone calorimeter test (Table 5) are consistent with those obtained at $700{ }^{\circ} \mathrm{C}$ using TGA. The values are higher at cone calorimeter but a correlation is observed.

\subsection{Thermal and fire behavior of PBS/natural fibers biocomposites}

\subsubsection{Influence of the nature of natural fibers}

As expected, the incorporation of $30 \mathrm{wt} \%$ natural fibers in PBS matrix reduces the thermal stability of the biocomposites [18]. The trend is more pronounced for lignocellulosic fibers (Fig. 4) compared to pure cellulose. A weight loss of about 20\% for PBS is reached at $370{ }^{\circ} \mathrm{C}$ compared to biocomposites which attain this percentage of degradation in the $350-360{ }^{\circ} \mathrm{C}$ range. However, the incorporation of natural fibers influences the mass residue. Indeed, biocomposites containing lignocellulosic fibers exhibit higher residue than the biocomposite containing cellulose. The theoretical mass residue was calculated from the experimental mass residues
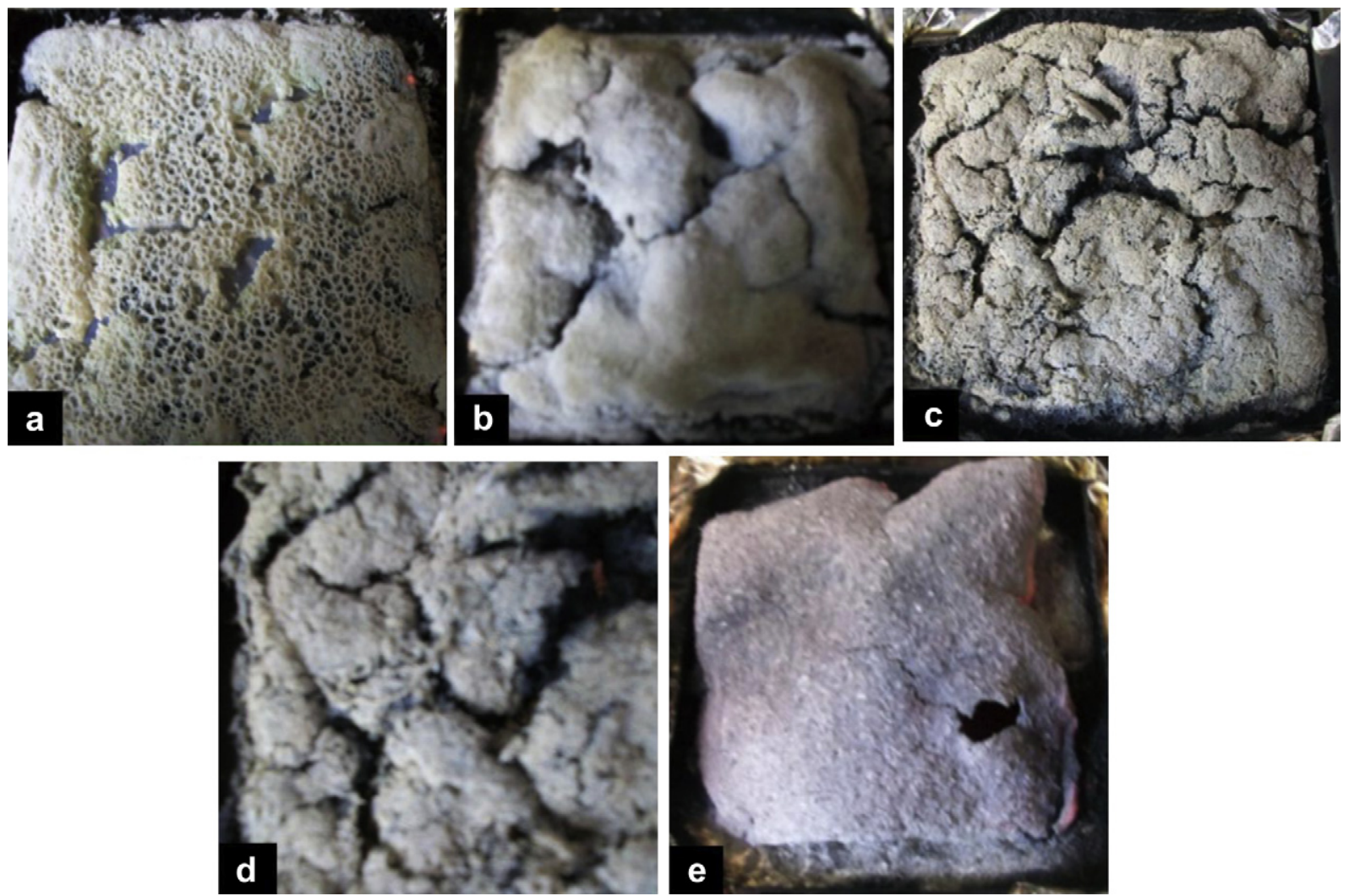

Fig. 8. Sample residues from cone calorimeter test (a) 70PBS30cel, (b) 70PBS30hem, (c) 70PBS30fl, (d) 70PBS30sug, (e) 70PBS30bam. 
Table 8

TTI, pHRR, THR, EHC, MARHE and residual mass of biocomposites with various natural fibers (cone calorimeter).

\begin{tabular}{lrlllll}
\hline Biocomposites & TTI (s) & $\begin{array}{l}\text { pHRR } \\
\left(\mathrm{kW} / \mathrm{m}^{2}\right)\end{array}$ & $\begin{array}{l}\text { THR } \\
(\mathrm{kJ})\end{array}$ & $\begin{array}{l}\text { EHC } \\
(\mathrm{kJ} / \mathrm{g})\end{array}$ & $\begin{array}{l}\text { MARHE } \\
\left(\mathrm{kW} / \mathrm{m}^{2}\right)\end{array}$ & $\begin{array}{l}\text { Mass } \\
\text { Res }(\%)\end{array}$ \\
\hline PBS & 150 & 485 & 873 & 21.0 & 213.8 & 0 \\
70PBS30cel & 96 & 385 & 984 & 19.8 & 239.6 & 1.7 \\
70PBS30fl & 61 & 270 & 884 & 19.5 & 202.0 & 5.5 \\
70PBS30hem & 67 & 332 & 818 & 18.1 & 212.4 & 10.0 \\
70PBS30sug & 74 & 313 & 862 & 19.3 & 201.3 & 5.4 \\
70PBS30bam & 43 & 339 & 884 & 19.6 & 246.0 & 9.7 \\
70PLA30fl & 53 & 245 & 687 & 14.6 & 178.8 & 4.6 \\
\hline
\end{tabular}

of the matrix and the fibers using the rule of mixture. For example, hemp based biocomposites should form a residue of $8.6 \%$ at high temperature. The experimental residual mass is systematically higher than the theoretical one. Hence an extra char formation is evidenced, revealing interactions between fiber and matrix. In addition, the rate of weight loss (in \%/min) is reduced when fibers are incorporated in the PBS (Table 6).

The incorporation of natural fibers allows a drop in the pHRR and HR, which is in-line with the literature [18] (Table 7 and Fig. 5). A theoretical pHRR ( $\mathrm{pHRR}_{\text {theo }}$ ) was calculated using the rule of mixture. Here again, the experimental pHRR is systematically lower than the theoretical one. This again suggests that there is an interaction between fibers and matrix, and that the fibers could exert a flame retardant effect in the bio-based composite. However, the difference between cellulosic fibers and lignocellulosic fibers in PCFC is not significant. Hence, the composition of fibers does not really influence the flammability (chemical effect) of the final biocomposite.

Nevertheless, some differences are noticeable in cone calorimeter test (Fig. 6). Indeed, contrary to PCFC tests (Fig. 5) that consider only the chemical effects, cone calorimeter tests highlight both chemical and physical effects [26]. The heat release rate curves are obtained at a heat flux of $35 \mathrm{~kW} / \mathrm{m}^{2}$. Firstly, the HRR curve of PBS is typical of a pure polymer. In this case, the TTI is relatively high because the degradation temperature is high. After the ignition, the combustion of volatiles (highly exothermic as seen by PCFC, Fig. 5) leads to a dramatic increase of the heat release rate. Afterwards, the HRR decreases also rapidly because of the rapid consumption of the fuel released by the polymer [27]. All reinforced biocomposites show lower pHRR than pure PBS, and particularly flax biocomposites. Cone calorimeter curves of reinforced biocomposites exhibit shorter time to ignition (TTI) than that of PBS. The natural
Table 9

TGA values of various biocomposites comprising different amounts of flax fibers.

\begin{tabular}{llll}
\hline Biocomposite & Mass Res $(\%)$ & $T_{20 \%}\left({ }^{\circ} \mathrm{C}\right)$ & DTG $\left({ }^{\circ} \mathrm{C} / \mathrm{min}\right)$ \\
\hline 70PBS30fl & 8.02 & 358 & -15.4 \\
80PBS20fl & 6.41 & 371 & -18.3 \\
85PBS15fl & 5.79 & 373 & -19.7 \\
90PBS10fl & 4.31 & 377 & -21.1 \\
\hline
\end{tabular}

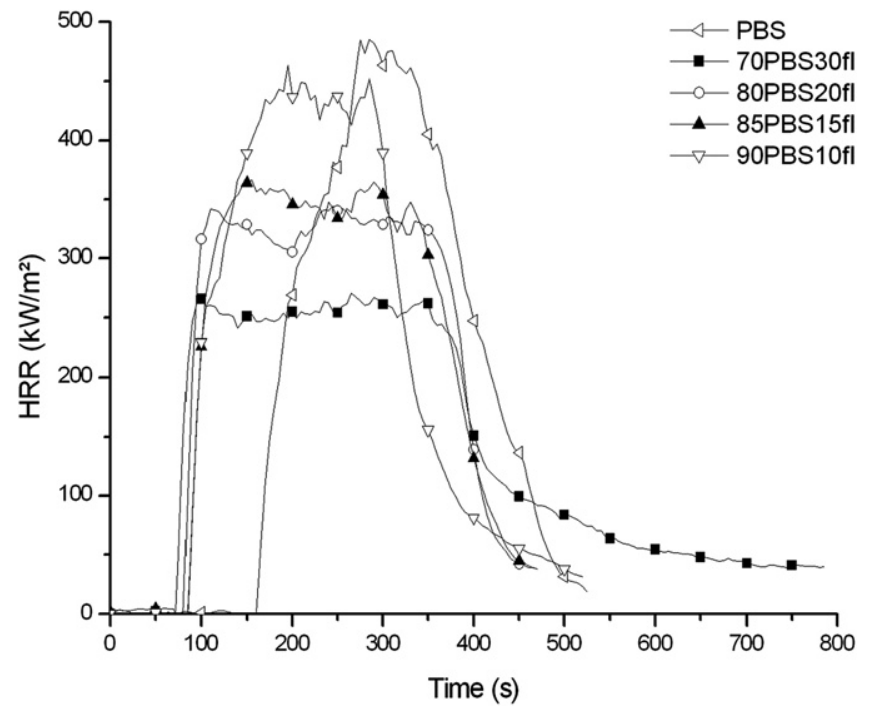

Fig. 10. HRR curves (cone calorimeter) of flax-based biocomposites.

fibers incorporated in the matrix causes an early ignition because the degradation of fibers occurs at a lower temperature (350$\left.380{ }^{\circ} \mathrm{C}\right)$ than the degradation of PBS $\left(390{ }^{\circ} \mathrm{C}\right)$. This observation coupled with TGA and PCFC results explain the effect of the natural fibers on the fire behavior of the biocomposites. We observed the same effect with the biocomposite based on PLA and lignocellulosic fibers (Fig. 6). After ignition, a first peak is observed due to the rapid decomposition of fibers, and then the HRR levels off because of the formation of a protective char layer. Thus, the degradation of the fibers leads to the formation of a layer acting as a barrier for heat and mass transport [6]. As shown in Fig. 7, this protective layer is mainly composed of natural fiber residue and it may be assumed that lignin play a significant role in the char formation. Afterwards, a second peak is sometimes observed and may be assigned to the
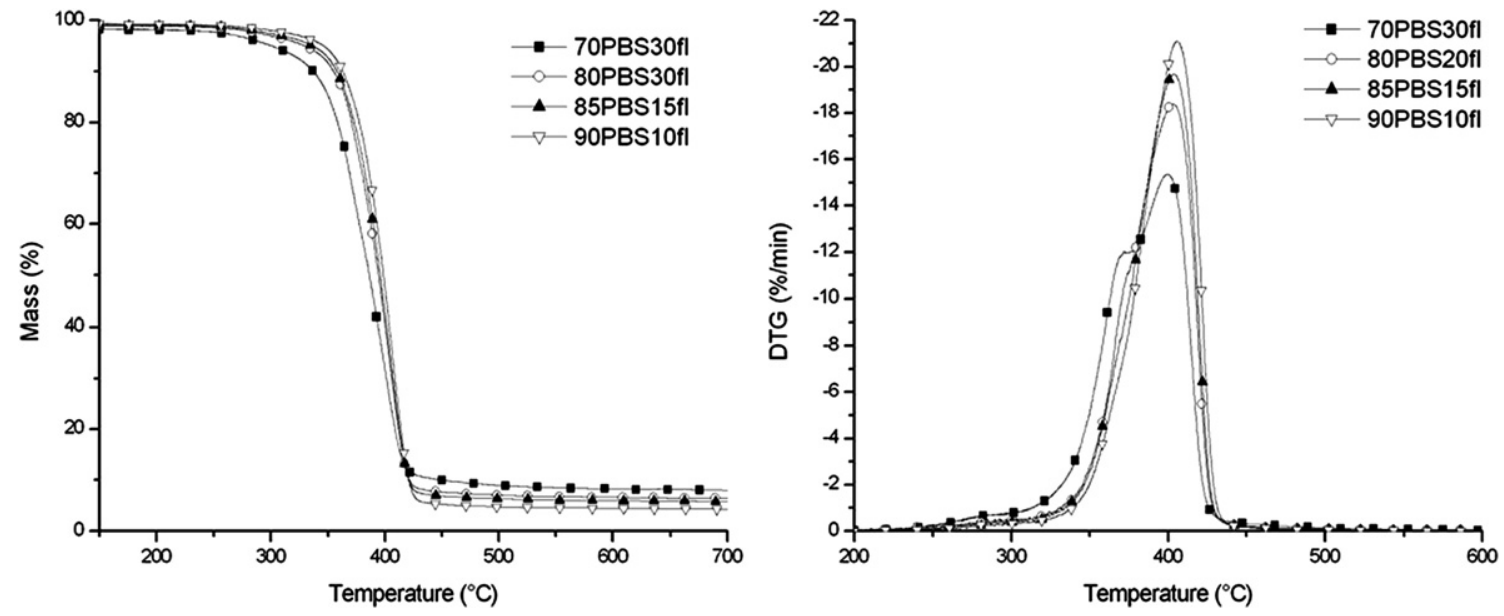

Fig. 9. TGA curves of various biocomposites comprising different amounts of flax fiber. 
Table 10

TTI, pHRR, theorical pHRR, THR, EHC, MARHE and residual mass of flax-based biocomposites (cone calorimeter).

\begin{tabular}{lclllll}
\hline Biocomposites & $\begin{array}{l}\text { TTI } \\
(\mathrm{s})\end{array}$ & $\begin{array}{l}\text { pHRR } \\
\left(\mathrm{kW} / \mathrm{m}^{2}\right)\end{array}$ & $\begin{array}{l}\text { THR } \\
(\mathrm{kJ})\end{array}$ & $\begin{array}{l}\text { EHC } \\
(\mathrm{kJ} / \mathrm{g})\end{array}$ & $\begin{array}{l}\text { MARHE } \\
\left(\mathrm{kW} / \mathrm{m}^{2}\right)\end{array}$ & $\begin{array}{l}\text { Mass } \\
\text { Res }(\%)\end{array}$ \\
\hline PBS & 150 & 485 & 873 & 21.0 & 213.8 & 0 \\
90PBS10fl & 77 & 464 & 938 & 19.8 & 276.6 & 2.4 \\
85PBS15fl & 76 & 367 & 910 & 19.2 & 251.6 & 3.2 \\
80PBS20fl & 73 & 345 & 906 & 19.3 & 249.1 & 5.2 \\
70PBS30fl & 61 & 270 & 934 & 19.5 & 202.0 & 5.5 \\
\hline
\end{tabular}

char cracking (Figs. 6 and 8) [28] and finally the HRR decreases. The cellulose-based biocomposite shows an intermediate curve between PBS and lignocellulosic biocomposite curves, because 70PBS30cel does not form a protective layer during the thermal degradation.

From Fig. 8 no cohesion is noticed for 70PBS30cel residue (1.7\%) contrary to those of 70PBS30hem (10.0\%), 70PBS30fl (5.5\%), 70PBS30sug (5.4\%) and 70PBS30bam (9.7\%), which exhibit the same types of cracks but with a cohesive residue. The barrier effect seems particularly significant for hemp fibers based biocomposite which presents the highest residue (10\% in Table 8 ) and the lowest EHC and THR. The MARHE indicates that the 70PBS30fl and the 70PBS30sug have the best fire properties.

\subsubsection{Influence of the amount of fibers}

The influence of the amount of natural fibers has been investigated using flax fibers, which have a good fire properties in PBS matrix $\left(\right.$ MARHE $\left.=202 \mathrm{~kW} / \mathrm{m}^{2}\right)$. It acts on the thermal degradation of the biocomposites since a higher amount leads to a lower thermal stability and a higher amount of residue (Fig. 9 and Table 9). However, it must be noticed that, degradation temperature with increasing flax fibers content is not very pronounced (from $405{ }^{\circ} \mathrm{C}$ for $10 \%$ to $399{ }^{\circ} \mathrm{C}$ for $30 \%$ ). The maximum rate of decomposition (DTG) decreases with increasing flax content but not linearly (Table 9). Moreover, the 70PBS30fl biocomposite exhibits two peaks in the DTG curve (Fig. 9). The first and lower peak is probably due to the decomposition of hemicellulose and lignin.

The addition of flax (even at amounts as low as 10\%) to PBS induces a dramatic drop of the TTI (from $150 \mathrm{~s}$ for PBS to $77 \mathrm{~s}$ for 90PBS10fl) (Fig. 10, Table 10) and this drop is slightly enhanced when more flax is added. This is explained by the poor influence of fiber content on the degradation temperature shown in TGA (Fig. 9). Over $10 \%$ of fibers content, the HRR curves exhibit rapidly a plateau which is typical of a barrier effect that controls the polymer degradation rate. A barrier effect is evidenced when flax content is over $10 \%$. This effect can be ascribed to a percolation threshold of fibers in the composites, hence favoring the cohesion of the residue. The difference between EHC of flax biocomposites is not significant, since there is no difference in the composition of the gaseous phase during the degradation of the biocomposites, on the opposite the mass residue significantly changes. There is more residue when the percentage of flax increases, and this entails a decrease of the pHRR $\left(270 \mathrm{~kW} / \mathrm{m}^{2}\right)$ and MARHE $\left(202 \mathrm{~kW} / \mathrm{m}^{2}\right)$ due to the formation of a larger char layer (Fig. 11) and its corresponding barrier effect.
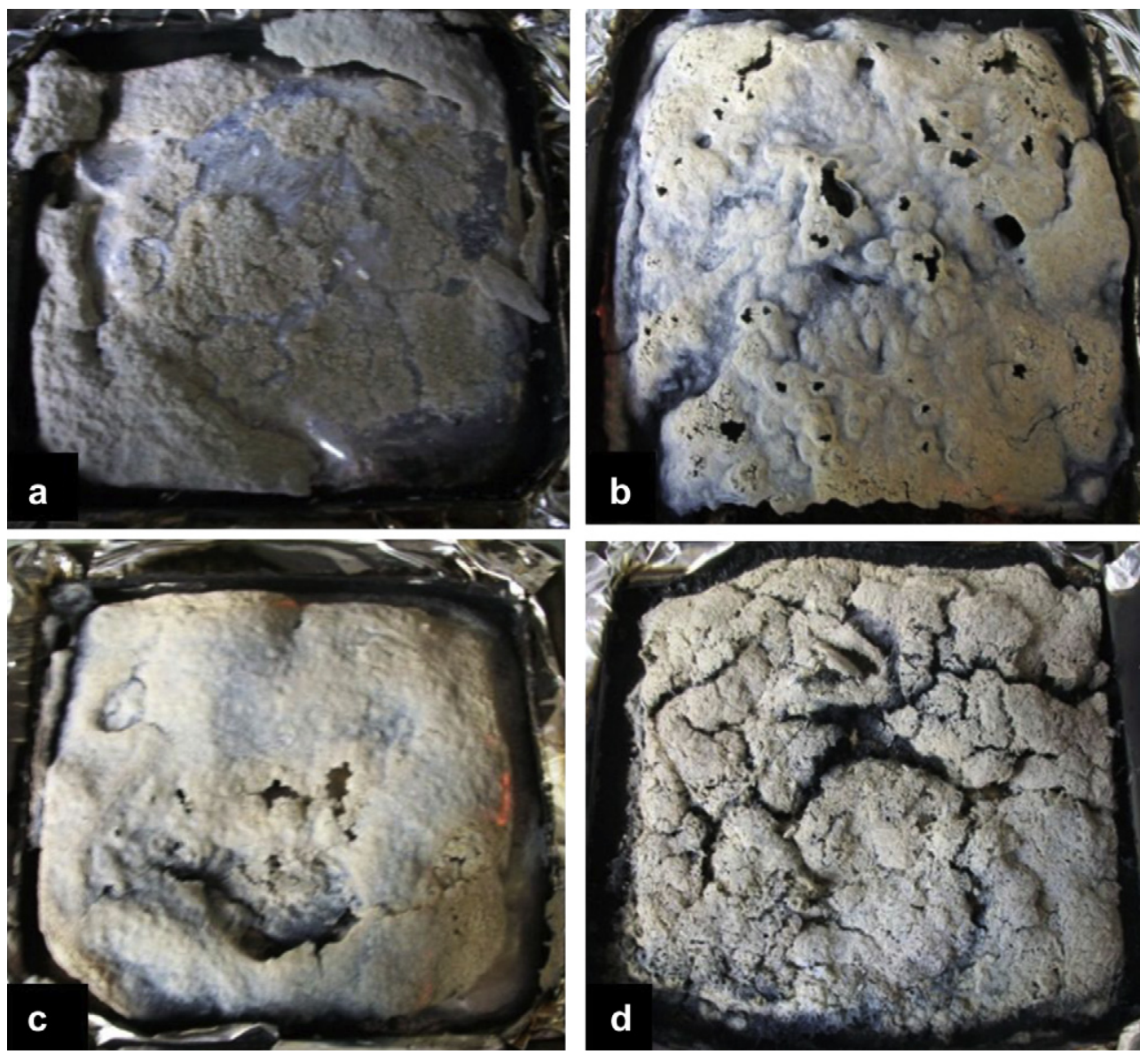

Fig. 11. Residue of samples from cone calorimeter tests: (a) 90PBS10fl, (b) 85PBS15fl, (c) 80PBS20fl, (d) $70 \mathrm{PBS} 30 \mathrm{fl}$. 
Table 11

TGA values of FR-biocomposites.

\begin{tabular}{lll}
\hline Biocomposites & Mass Res at $700{ }^{\circ} \mathrm{C}(\%)$ & $T_{20 \%}\left({ }^{\circ} \mathrm{C}\right)$ \\
\hline PBS & 0.75 & 370 \\
95PBS5APP & 5 & 346 \\
70PBS30fl & 6.8 & 358 \\
65PBS5APP-30fl & 14 & 317 \\
\hline
\end{tabular}

\subsection{Thermal and fire behavior of FR-biocomposites based on APP}

Ammonium polyphosphate is often used as main component of intumescent flame retardant systems $[27,28]$. It has also been used in biocomposites $[10,29]$. When APP is incorporated in PBS, a drop in degradation temperature is observed $\left(T_{20}^{\circ}=370{ }^{\circ} \mathrm{C}\right.$ for the PBS against $T_{20 \%}^{\circ}=346{ }^{\circ} \mathrm{C}$ for the 95PBS5APP, Table 11). Since APP decomposes by releasing water [30,31], an early degradation of PBS due to hot hydrolysis is observed. But at the same time, APP enables the formation of a $5 \%$ residue (Table 11, Fig. 12). The addition of APP in flax biocomposite also decreases the thermal stability. The degradation of the composite occurs in two steps. The first one at low temperature corresponds to the degradation of the fibers and their phosphorylation $[10,32]$. The second one corresponds to the degradation of the polymer matrix (Fig. 12). A high percentage of residue is obtained for the fire retarded biocomposite. APP generates both interactions with the fiber and particularly with lignin contained in flax fibers [33] and with PBS.

The addition of ammonium polyphosphate (APP) in PBS and in PBS/flax leads to a decrease of the TTI at cone calorimeter (Fig. 13). Moreover, APP also entails a strong increase in pHRR for PBS. This is directly linked to APP decomposition at low temperature when it is added to PBS and PBS/flax (described previously by TGA in Fig. 12). The residues obtained after cone calorimeter tests (Table 12) are in agreement with those of TGA analysis and highlight the formation of a strong char barrier as observed in the PP/flax by Schartel et al. [34]. This thermal layer induces the decrease of pHRR and MARHE of the 65PBS5APP-30fl biocomposite by limiting heat and mass transfer.

The effective heat of combustion (EHC) in Table 12 corresponds to the heat released per gram of mass loss, that is to say the chemical effectiveness of the fire retardant. APP releases ammonia and water which dilutes the gaseous phase and leads to the formation of a carbonaceous residue.

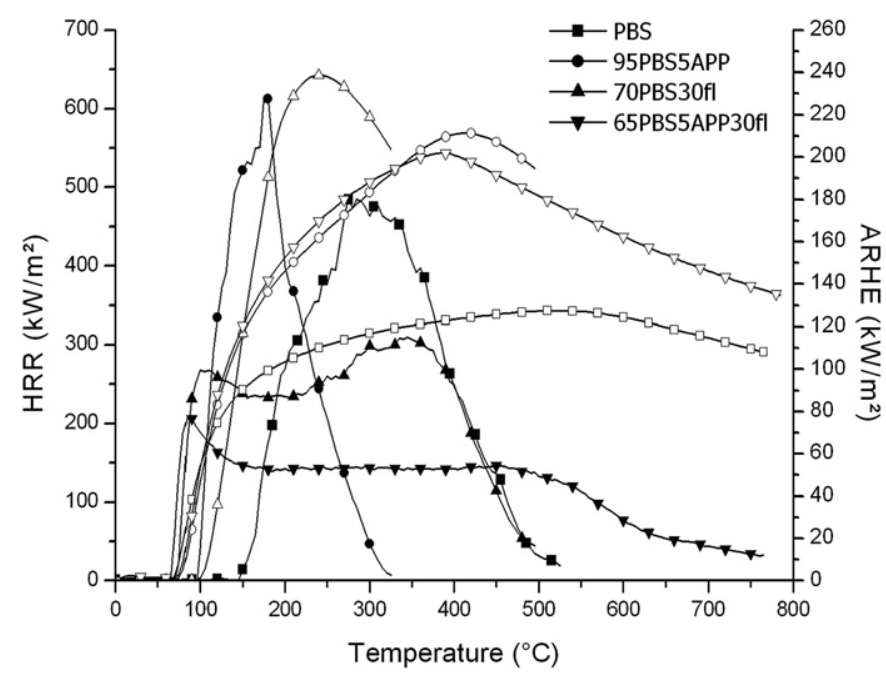

Fig. 13. Cone calorimeter curves of FR-biocomposites: the curves with full symbols represent the HRR vs temperature whereas the curves with empty symbols represent the ARHE vs temperature.

Table 12

Cone calorimeter values for PBS, PBS/flax biocomposite and FR-biocomposite.

\begin{tabular}{lrllll}
\hline Biocomposites & TTI $(\mathrm{s})$ & $\begin{array}{l}\text { pHRR } \\
\left(\mathrm{kW} / \mathrm{m}^{2}\right)\end{array}$ & EHC $(\mathrm{kJ} / \mathrm{g})$ & $\begin{array}{l}\text { MARHE } \\
\left(\mathrm{kW} / \mathrm{m}^{2}\right)\end{array}$ & Mass Res (\%) \\
\hline PBS & 150 & 485 & 21.0 & 213.8 & 0 \\
95PBS5APP & 86 & 614 & 19.7 & 238.7 & 4.7 \\
70PBS30fl & 61 & 270 & 19.5 & 211.4 & 5.5 \\
65PBS5APP-30fl & 55 & 208 & 16.8 & 127.4 & 17 \\
\hline
\end{tabular}

The addition of APP into the biocomposite (70PBS30fl) leads to a significant decrease of the EHC $[35,36]$. This result (compared to the result obtained by adding APP to PBS) clearly highlights the interaction between APP and flax fibers. During cone calorimeter test, the thermal degradation of APP leads to the formation of phosphoric acid, which combines with the hydroxyl function of flax forming a phosphorus ester. This ester catalyzes the dehydration of the fibers and leads to the formation of a carbonaceous structure [7]. Hence, the vapor phase composition is changed and the released energy is lower.
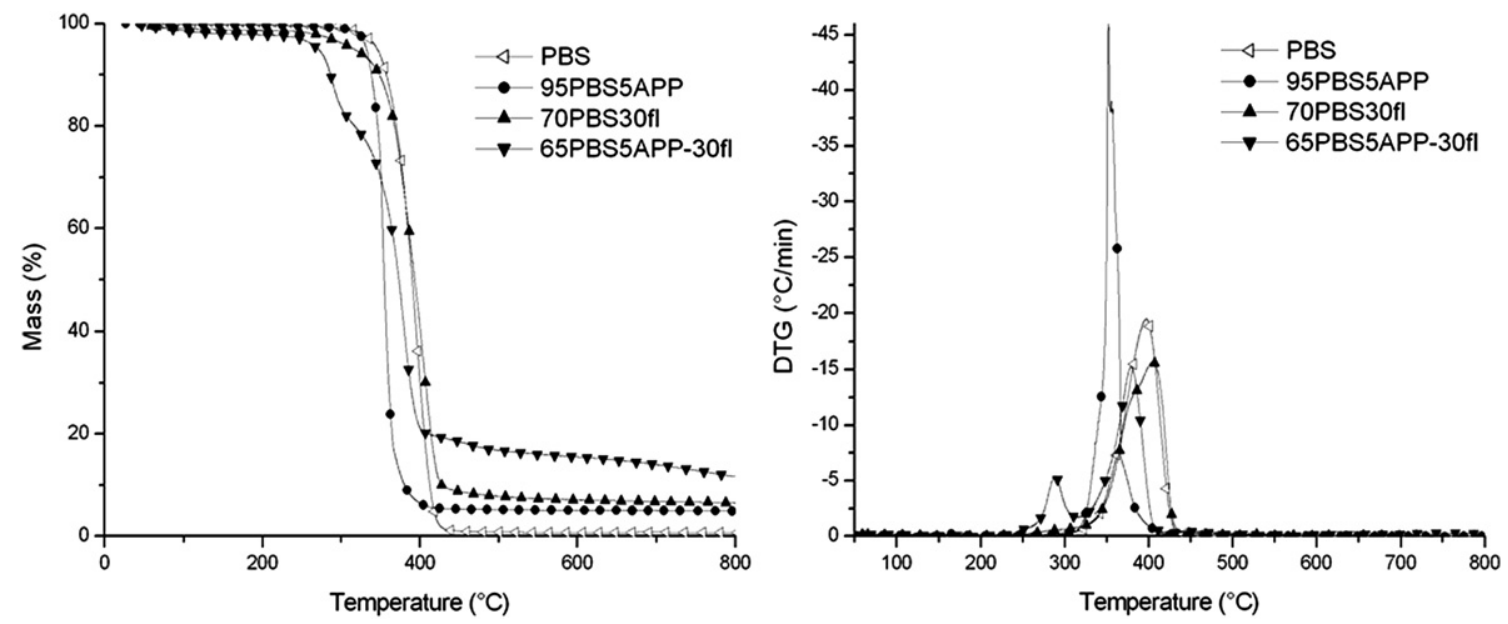

Fig. 12. TGA curves of FR-biocomposites. 


\section{Conclusion}

In this study, the importance of lignin in natural fibers and PBS/ natural fibers biocomposites as low flammable compound has been highlighted. Moreover, in most cases, a char layer is observed after cone calorimeter test. This char layer leads to a reduction of the pHRR because of the limitation of mass and thermal transfer. But it has been shown that a minimum fiber content is required to form a fire protective layer. The addition of APP as fire retardant agent entails significant changes for thermal and fire degradation of PBS biocomposites. It leads to an early degradation of PBS but it enables the matrix charring and causes the phosphorylation of the flax fibers. These combined effects are beneficial to the formation of a strong char barrier and a significant decrease of the pHRR $\left(208 \mathrm{~kW} / \mathrm{m}^{2}\right.$ for the 65PBS5APP-30fl). An interesting outlook to this work would be to graft the surface of fibers with adequate fire retardants. This would improve both fire and mechanical properties of the biocomposite by enhancing the interface between PBS matrix and flax fibers.

\section{Acknowledgments}

We are grateful to Bamboo Fiber Technology for donating bamboo fibers.

\section{Appendix A. Supplementary data}

Supplementary data related to this article can be found at http:// dx.doi.org/10.1016/j.polymdegradstab.2012.10.026.

\section{References}

[1] Zeikus JG, Jain MK, Elankovan P. Biotechnology of succinic acid production and markets for derived industrial products. Appl Microbiol Biotechnol 1999; 51(5):545-52.

[2] Xie Y, Hill CAS, Xiao Z, Militz H, Mai C. Silane coupling agents used for natural fiber polymer composites: a review. Compos Appl Sci Manuf 2010;41(7):806-19.

[3] Bourmaud A, Riviere J, Le Duigou A, Raj G, Baley C. Investigations of the use of a mussel-inspired compatibilizer to improve the matrix-fiber adhesion of a biocomposite. Polym Test 2009;28(6):668-72.

[4] Belgacem MN, Gandini A. The surface modification of cellulose fibres for use as reinforcing elements in composite materials. Compos Interface 2005;12(1): 41-75.

[5] Faruk O, Bledzki AK, Find HP, Sain M. Biocomposites reinforced with natural fibers: 2000-2010. Prog Polym Sci 2012;37(11):1552-96.

[6] Hapuarachchi TD, Peijs T. Multiwalled carbon nanotubes and sepiolite nanoclays as flame retardants for polylactide and its natural fibre reinforced composites. Compos Appl Sci Manuf 2010;41(8):954-63.

[7] Suardana NPG, Ku MS, Lim JK. Effects of diammonium phosphate on the flammability and mechanical properties of bio-composites. Mater Des. 2011 32(4):1990-9.

[8] Chaiwong C, Tunma S, Sangprasert W, Nimmanpipug P, Boonyawan D. Graft polymerization of flame-retardant compound onto silk via plasma jet. Surf Coat Tech 2010;204(18-19):2991-5.

[9] Matkó S, Toldy A, Keszei S, Anna P, Bertalan G, Marosi G. Flame retardancy of biodegradable polymers and biocomposites. Polym Deg Stab 2005;88(1): $138-45$.

[10] Shumao L, Jie R, Hua Y, Tao Y, Weizhong Y. Influence of ammonium polyphosphate on the flame retardancy and mechanical properties of ramie fiberreinforced poly(lactic acid) biocomposites. Polym Int 2009;59(2):242-8.
[11] Chen D, Li J, Ren J. Combustion properties and transference behavior of ultrafine microencapsulated ammonium polyphosphate in ramie fabricreinforced poly(L-lactic acid) biocomposites. Polym Int 2011;60(4):599-606.

[12] Yao F, Wu Q, Lei Y, Guo W, Xu Y. Thermal decomposition kinetics of natural fibers: activation energy with dynamic thermogravimetric analysis. Polym Deg Stab 2008;93(1):90-8.

[13] Kozłowski R, Władyka-Przybylak M. Flammability and fire resistance of composites reinforced by natural fibers. Polym Advan Technol 2008;19(6): 446-53.

[14] Bledzki AK, Reihmane S, Gassan J. Properties and modification methods for vegetable fibers for natural fiber composites. J Appl Polym Sci 1996;59(8): 1329-36.

[15] Didane N, Giraud S, Devaux E. Fire performances comparison of back coating and melt spinning approaches for PET covering textiles. Polym Deg Stab 2012; 97(7):1083-9.

[16] Lyon R, Walters RN. Pyrolysis combustion flow calorimetry. J Anal Appl Pyrol 2004;71(1):27-46.

[17] Albano C, Gonzalez J, Ichazo M, Kaiser D. Thermal stability of blends of polyolefins and sisal fiber. Polym Deg Stab 1999;66(2):179-90.

[18] Chapple S, Anandjiwala R. Flammability of natural fiber-reinforced composites and strategies for fire retardancy: a review. J Thermoplast Compos 2010; 23(6):871-93

[19] Manfredi LB, Rodríguez ES, Wladyka-Przybylak M, Vázquez A. Therma degradation and fire resistance of unsaturated polyester, modified acrylic resins and their composites with natural fibres. Polym Deg Stab 2006;91(2): 255-61.

[20] Manikandan Nair KC. Thomas S, Groeninck G. Thermal and dynamic mechanical analysis of polystyrene composites reinforced with short sisal fibres. Compos Sci Technol 2001;61(16):2519-29.

[21] Moriana R, Vilaplana F, Karlsson S, Ribes-Greus A. Improved thermomechanical properties by the addition of natural fibres in starch-based sustainable biocomposites. Compos Appl Sci Manuf 2011;42(1):30-40.

[22] Lewin M, Basch A. Flame retardant polymeric materials. In: Lewin M, Atlas SM, Pearce EM, editors. Structure, pyrolysis, and flammability of cellulose, vol. 2. New York: Plenum Press; 1978. p. 1-40.

[23] Marcovich NE, Reboredo MM, Aranguren MI. Modified woodflour as thermoset fillers II. Thermal degradation of woodflours and composites. Thermochim Acta 2001;372(1-2):45-57.

[24] Hosoya T, Kawamoto H, Saka S. Cellulose-hemicellulose and cellulose-lignin interactions in wood pyrolysis at gasification temperature. J Anal Appl Pyrol 2007:80(1):118-25.

[25] Lewin M. Unsolved problems and unanswered questions in flame retardance of polymers. Polym Deg Stab 2005;88(1):13-9.

[26] Sonnier R, Ferry L, Longuet C, Laoutid F, Friederich B, Laachachi A, et al Combining cone calorimeter and PCFC to determine the mode of action of flame-retardant additives. Polym Advan Technol 2011;22(7):1091-9.

[27] Mouritz AP, Mathys Z, Gibson A. Heat release of polymer composites in fire. Compos Appl Sci Manuf 2006;37(7):1040-54.

[28] Schartel B, Hull TR. Development of fire-retarded materials - interpretation of cone calorimeter data. Fire Mater 2007;31(5).

[29] Fontaine G, Bourbigot S. Intumescent polylactide: a nonflammable material. J Appl Polym Sci 2009;113(6):3860-5.

[30] Reti C, Casetta M, Duquesne S, Bourbigot S, Delobel R. Flammability properties of intumescent PLA including starch and lignin. Polym Advan Technol 2008; 19(6):628-35

[31] Le Bras $M$, Duquesne $S$, Fois $M$, Grisel $M$, Poutch $F$. Intumescent polypropylene/flax blends: a preliminary study. Polym Deg Stab 2005;88(1):80-4.

[32] Kandola KB, Horrocks AR. Complex char formation in flame-retarded fibreintumescent combinations - II. Thermal analytical studies. Polym Deg Stab 1996;54(2-3):289-303.

[33] De Chirico A, Armanini M, Chini P, Cioccolo G, Provasoli F, Audisio G. Flame retardants for polypropylene based on lignin. Polym Deg Stab 2003;79(1): 139-45.

[34] Schartel B, Braun U, Schwarz U, Reinemann S. Fire retardancy of polypropylene/flax blends. Polymer 2003;44(20):6241-50.

[35] Riva A, Camino G, Fomperie L, Amigouët P. Fire retardant mechanism in intumescent ethylene vinyl acetate compositions. Polym Deg Stab 2003;82(2): 341-6.

[36] Laoutid F, Bonnaud L, Alexandre M, Lopez-Cuesta JM, Dubois P. New prospects in flame retardant polymer materials: from fundamentals to nanocomposites. Mat Sci Eng R 2009;63(3):100-25. 